\title{
Autosomal dominant spastic paraplegia type 19
}

INSERM

\section{Source}

INSERM. (1999). Orphanet: an online rare disease and orphan drug data base. Autosomal dominant spastic paraplegia type 19. ORPHA:100999

Autosomal dominant spastic paraplegia type 19 is a pure form of hereditary spastic paraplegia characterized by a slowly progressive and relatively benign spastic paraplegia presenting in adulthood with spastic gait, lower limb hyperreflexia, extensor plantar responses, bladder dysfunction (urinary urgency and/or incontinence), and mild sensory and motor peripheral neuropathy. 